\title{
Learning to navigate: the centrality of instructions and assessments for developing students' professional competencies in simulator-based training
}

\author{
Charlott Sellberg ${ }^{1}$ (1) $\cdot$ Olle Lindmark $^{2} \cdot$ Hans Rystedt $^{1}$
}

Received: 6 December 2017 / Accepted: 7 March 2018 / Published online: 17 March 2018

(C) The Author(s) 2018

\begin{abstract}
Despite the promises of simulations to contribute to learning in safe-critical domains, research suggests that simulators are poorly implemented in maritime education and training systems. From the current state of research, it is far from evident how instruction in simulator-based should be designed and how skills trained in bridge simulators should be assessed and connected to professional practice. On this background, this article aims to investigate the role of instructions and assessments for developing students' professional competencies in simulation-based learning environments. The research draws on ethnographic fieldwork and detailed analyses of video-recorded data to examine how maritime instructors make use of simulator technologies in a navigation course. Our results reveal an instructional practice in which the need to account for general principles of good seamanship and anti-collision regulations is at the core of basic navigation training. The meanings of good seamanship and the rules of the sea are hard to teach in abstraction because their application relies on an infinite number of contingencies that have to be accounted for in every specific case. Based on this premise, we stress the importance of instructional support throughout training (from briefing thorough scenario to debriefing) in order for the instructor to bridge theory and practice in ways that develop students' competencies. Our results highlight, in detail, how simulator technologies enable displaying and assessing such competencies by supporting instructors to continuously monitor, assess, and provide feedback to the students during training sessions. Moreover, our results show how simulator-based training is related to the work conditions on board a seagoing vessel through the instructor's systematic accomplishments. Finally, our
\end{abstract}

Charlott Sellberg

charlott.sellberg@gu.se

1 Department of Education, Communication and Learning, University of Gothenburg, Box 300, SE-405 30 Gothenburg, Sweden

2 Department of Mechanics and Maritime Sciences, Chalmers University of Technology, SE-412 96 Gothenburg, Sweden 
results highlight the close relationship between technical and non-technical skills in navigation, and how these are intertwined in training for everyday maritime operations.

Keywords Maritime education and training (MET) · Simulator-based training · Instruction · Assessment · Debriefing

\section{Introduction}

Today, the use of simulators is mandatory for certain parts of the curriculum for maritime education and training (MET) and is regulated by international conventions, that is, by the Standards of Training, Certification and Watchkeeping for Seafarers (STCW). In order to ensure that future mariners are able to act in proper and safe manners, it is stressed in STCW that simulators are to be used for both training and assessment. One of the major recent updates of the STCW Convention-the 2010 Manila amendments - has a greater focus on technical proficiency and so-called non-technical skills compared to previous versions of the convention. The technical skills relate to handling the equipment of the ship, while the non-technical are often described as cognitive and communicative skills, such as situation awareness and decision-making, as well as skills involving teamwork, such as leadership and communication (Flin 2008). Although the use of simulators for training and assessing technical proficiency and non-technical skills is well established and regulated by international standards in MET, we found few empirical studies on simulator-based maritime training and assessment (Sellberg 2017a). Hence, there is a need for further empirical studies that explore the role of instruction and assessment in simulation-based maritime training.

Simulators have been shown to provide opportunities for training in high-risk professions such as shipping, aviation, and healthcare in a risk-free manner (e.g. Dahlström et al. 2009). In the maritime industry, simulators provide opportunities to train skills that are time-consuming and costly to practice on board a real vessel (Hanzu-Pazara et al. 2008). The controlled simulator environment also has pedagogical advantages, as exercises can be designed to train and assess specific learning outcomes in a way that is adjusted to the level of the students' current competence (Maran and Glavin 2003). However, besides the potential for learning, there may be limitations to what can be experienced in a simulator and during simulation. Hontvedt and Arnseth (2013) suggest that maritime work practices rely on aspects of space and temporality in an intricate way that hardly can be simulated in an educational setting. Moreover, Hontvedt (2015a), based on analysis of maritime pilot training on two different high-fidelity bridge simulators, concluded that the lack of photorealism and fidelity in the simulator can affect the dynamics of the exercises negatively. A lack of simulator fidelity may cause participants to simply manipulate the simulated model instead of training for professional work. Hontvedt (2015a) argues that training sessions have to be carefully configured in order for such pitfalls to be avoided. Studies examining the use of simulators in maritime training are actually direct warnings about simulator-based training and assessment as being poorly implemented in the MET system (Emad and Roth 2008; Gekara et al. 2011; Sampson et al. 2011). The problems reported concern both simulator misuse and lack of knowledge concerning how to 
provide efficient training and valid assessment in simulators. While several studies highlight the importance of proficient instruction during simulator-based training in order to accomplish learning objectives, in research conducted until now, it is far from evident how simulator-based should be designed and how skills trained in the simulator relates to professional practice (cf. Ali 2008; Hanzu-Pazara et al. 2010; Hontvedt 2015b; Hontvedt and Arnseth 2013).

In regard to these challenges, the aim of this study is to investigate the role of instructions and assessments for developing students' professional competencies in simulation-based learning environments. The analyses draw on ethnographic fieldwork and detailed interaction analyses of video-recorded data from simulator training sessions in a navigation course by examining how maritime instructors make use of simulator technologies for instruction and formative assessment in order to develop students' professional competencies (cf. Heath et al. 2010). In particular, the following two research questions are under scrutiny: (1) How does the maritime instructor connect general learning objectives to specific situations during the different phases of training in the simulator? (2) How can the maritime instructor handle the lack of fidelity of the simulator in preparing the students for the conditions on board a seagoing vessel? In this way, this study contributes empirically grounded knowledge of how simulator technologies can be practically used for fostering professional competencies.

\section{Background}

As stated in the introduction, a recent literature review of the use of simulators in bridge operation training showed that, although the use of simulators is both well established and well regulated in maritime education, few empirical studies have addressed the pedagogical aspects of simulator-based training in this domain (Sellberg 2017a). The importance of instructional support during simulator-based training is seen in the results from studies on simulations in other domains, such as healthcare and dentistry (Hindmarsh et al. 2014; Rystedt and Sjöblom 2012). In a study of students training together with professional pilots in a full-mission simulator, Hontvedt and Arnseth (2013) found that expert feedback is crucial in order to structure simulator training in a way that enhances professional knowledge.

\subsection{The organisation of simulator-based training}

Simulation-based training is regularly organised into three different phases. First, an introduction to the day's assignment is usually made through a briefing. In the literature, this phase is described as being commonly focused on practical information, the sharing of resources, and the learning objectives of the assignment (e.g. Wickers 2010; Fanning and Gaba 2007). After the introduction, a scenario plays out in the simulator. Emad (2010) describes how a maritime instructor is expected to organise a scenario in the simulator by accounting for how the instructor assigns each student team with the duties of a ship's bridge team. After that, the instructor gives the student bridge team a specific navigational task and runs the simulation while supervising the students' activities. Through this design, novices such as students can take on the 
responsibilities of officers in educational settings. The role of the instructor is described as one that oversees, facilitates, and moderates, gradually decreasing his support in line with the students' developing skills.

Lastly, a debriefing is carried out. In the literature, debriefing is described as a post-experience analysis of and reflection on the event. An almost unanimous conclusion in the research across domains highlights the importance of post-simulation debriefing (Dieckmann et al. 2008; Fanning and Gaba 2007; Wickers 2010). Allowing for retrospective feedback and reflection is necessary for participants to learn from their experiences in a way that teaches them how to manage future situations. In general, a structure is suggested involving three phases: a description of what happened, an analysis of what should be done differently in the future, and a conclusion that summarise the lessons learned (Fanning and Gaba 2007).

In debriefing, it is common to use different technologies for feedback. In aviation and maritime training, different forms of visualisation have been used to revisit and learn from the exercises (Hontvedt and Arnseth 2013; Roth and Jornet 2015). While empirical studies on the use of playback technologies in navigation training are still lacking, results from studies of simulations in healthcare show that the use of high-fidelity debriefings has pedagogical potential (Neill and Wotton 2011). In teamwork training in healthcare, for instance, the use of video is recommended to assist debriefings (Dieckmann et al. 2008). A pedagogical rationale for using video is that it provides a record of the actions taken during a scenario, and that record allows the participants to view their prior actions from an observer's perspective. The main idea is that gaining an observer's perspective on one's own conduct allows the participants to see how they performed, instead of how they thought they performed, and this is expected to reduce 'hindsight bias' in debriefing (Fanning and Gaba 2007). Video-assisted debriefings, among other things, provide a third-person perspective on one's own conduct and make it possible to reconceptualise prior events in professionally relevant ways (Johansson et al. 2017). Such outcomes, however, demand substantial efforts by facilitators to highlight critical aspects of what is shown and to demonstrate how the situation should be understood (Goodwin 1994). This conclusion concurs with studies in other educational fields that point to the need for systematic instruction if students are to be able to make sense of film clips of their own conduct (Erickson 2007). Although video as a feedback technology is quite different from the kinds of visualisation tools common in navigation training, it points to the fact that visualisations are far from self-explanatory and there is a need to scrutinise instructors' practical use of feedback technologies for instructional purposes.

\subsection{The relevance of simulator-based training for professional work}

A common assumption about simulation training is that the resemblance between the simulations and the conditions of authentic work settings, often expressed in terms of fidelity, allows for the transfer of skills and knowledge to the work setting. A further assumption is that the more similar the simulation is to the situation it is intended to represent, the greater the possibility that such transfer will occur. This relationship, however, has been questioned because higher fidelity regarding the physical properties of the simulator does not necessarily correlate with effective learning (Hamstra et al. 
2014). Instead, the fidelity of the simulation should be seen as relative to the work tasks demands.

Instead of focusing on fidelity and transfer in the traditional sense, this study puts the analytical focus on instructors' and students' interactions in the simulation environment. In doing this, we rely on empirical studies of how instructors make situations in the simulation relevant to professional work (e.g. Rystedt and Sjöblom 2012; Johnson 2007; Escher et al. 2017; Hontvedt and Arnseth 2013; Sellberg 2017b). Using this approach, it follows that the simulations' relevance for learning good seamanship is not an effect of the simulators' fidelity per se, but rather a result of the facilitators' instructions. As pointed out by Hontvedt and Arnseth (2013) and Sellberg (2017b), instructors systematically close a manifold of gaps between the conditions of the simulation and how tasks should be managed on board, such as the consequences of fast rudder movements or machine failures that are not represented in the simulator. Further, studies in other domains of professional education have shown how discrepancies between the simulations and actual work can function as a means for highlighting critical principles at the core of professional conduct (e.g. Hindmarsh et al. 2014). This does not mean that the technical properties of the simulator are unimportant. By highlighting the students' management of authentic tasks, such as navigating in narrow waters by means of the tools of the trade, the focus is put on how simulator environments are deliberately utilised as educational resources for instruction and assessment.

To summarise, the results seen so far highlight both aspects of simulator fidelity as well as the role and significance of instructional support during simulations as important for learning the maritime profession. This research project adds to these results with knowledge on how instructions in a simulator environment are carried out, but also why learning practices should be designed in certain ways.

\section{Research approach}

In both the learning sciences and human factors research, there are two co-existing research paradigms: cognitive psychology and situated/socio-cultural perspectives (e.g. Ludvigsen and Arnseth 2017; Lützhöft et al. 2010). The first draws on classical cognitive theories for testing hypotheses based on variables in relation to learning. In previous studies of simulator-based training, the cognitive approach is seen through research designs that strive to isolate skills for training and thus reflects an interest in underlying cognitive models during learning activities (e.g. Chauvin et al. 2009; Saus et al. 2010). Instead of taking a classic cognitive approach, the current study draws on theories that situate work and learning in social, material, and cultural contexts (Goodwin 1994; Hutchins 1995; Suchman 2007). This approach implies an interest in the specific details of educational activities in terms of the interactions between instructors, students, and the simulator environment, with a focus on how the students develop their perception and understanding of professional practice. The implications of taking a situated approach is that technical proficiency and non-technical skills are seen as intricately intertwined in simulator training of maritime operations. In particular, research in this tradition highlights tight relationships between tasks, instruction, and technology (cf. Greiffenhagen 2008; Hontvedt 2015a, b). In maritime educational research, few studies prior to this study take a situated perspective on simulator-based 
training. However, our results show promise, contributing to a new understanding of how students develop professional mariner knowledge (cf. Hontvedt and Arnseth 2013; Hontvedt 2015a, b).

\subsection{The empirical case}

The focus in this study is learning activities situated in a bridge operation simulator, consisting of five high-fidelity simulators that combine the physical space of a ship's bridge with digital projections of the marine environment. The bridges can be monitored from an instructors' room where several computer screens are showing different aspects of the students' work: the settings of instruments, audio-visual recordings of the students' team work, and data that makes it possible to monitor the students' lookout on the marine environment as they see it during exercises. An overall view of the scenario as a whole is also possible: on one screen, the actions of each vessel is visualised from a bird's eye perspective. Next to the simulators is the briefing room. It is a classroom setup for group discussions in the briefing and debriefing phases of training.

The navigation course that was selected for further examination is part of a four-year master mariner program and takes place during the second year. It consists of both theoretical and practical learning activities: theoretical lectures that are mainly focused on the use of navigation technologies, i.e. Radar and ARPA equipment, the Regulations for Preventing Collisions at Sea (COLREG) that serves as 'rules of the road' at sea, as well as communication between vessels and bridge team communication and operations. The practical exercises consist of five mandatory simulation-based training sessions based on two to three different scenarios. The scenarios are designed to train the appropriate use of ARPA functions in different traffic and weather conditions, and students' understanding of strengths and limitations of the automated system. Another learning objective stated in the curriculum is to be able to interpret and apply COLREG in different situations. A scenario for training these kinds of skills is for example to navigate in the shallow waters near the coast of Skagen, to navigate in the narrow and trafficked waters of the Great Belt Strait, or to connect, cross, or follow the traffic separation scheme (TSS) in the highly trafficked English Channel.

\subsection{Methods}

The research design is based on three well-established principles for video-based research (Heath et al. 2010). The first principle is to explore human-technology interactions as they naturally unfold in the setting under study. This implies that instructional activities at the simulator centre were studied with the intention of manipulating the activities taking place during training as little as possible. Second, when studying highly technical workplaces in complex domains, such as maritime navigation training, ethnographic fieldwork is considered essential for developing an understanding of the practice and context where the interaction takes place (Heath et al. 2010). Fieldwork is helpful to carry out at different periods in the research process, at times when different questions arise in analysis (Heath et al. 2010). In the first phase of data collection (autumn 2013), we conducted observations with the aim of familiarising with the field of maritime education and gaining an overview of the simulator centre. These observations concerned several different simulators and types of activities: cargo 
operations, engine control operations, and radio communication. However, the main focus when collecting data was on different navigational tasks, and therefore most observations have been conducted in the different navigation simulators. Structured fieldwork continued during spring 2014 with the aim of as researchers gaining first-hand experience in using the simulators. Training sessions were carried out on the bridge operation simulator. From 2015 until 2018, extensive time was spent in the simulator centre as part of the prolonged ethnographic engagement although fieldwork was becoming less structured when becoming a member of the setting. Fieldtrips to different simulator centres across Europe became a part of the ethnography, visiting maritime schools and simulator centres in Sweden, Denmark, Great Britain, and Bulgaria. During fieldwork, informal interviews were important sources of information on the setting and of work practices throughout the research project. The aim has been to ask open-ended questions that seek to capture the point of views of the respondents without any preconceptions. Informal interviews have been carried out with six of the instructors involved in the navigational courses under study, but also with instructors from other simulator facilities, contributing with valuable insights and perspectives on training and assessment in simulator environments.

The third principle emphasises the complex relationship between temporal, technical, and social environments in simulation-based training (Heath et al. 2010). This makes video data important because video makes possible stable records with which to analyse the interactions that take place during training. Derry et al. (2010) describe video research as a non-linear process, moving back and forth between different phases: planning a study, collecting data, and then selecting and analysing selection of data. This is the case also in this project where simulator-based training has been video recorded at different occasions. The main reason for this design was to ensure that we capture the setting and the activities in a way that will allow for analysis of the research questions in a sufficient manner. The highly technical simulator environment is a challenging setting to capture. It is both technically mediated and socially and spatially distributed, consisting of several different rooms and participants. These aspects make finding the action and framing it in a good way a non-trivial task when filming at the simulator centre. In April 2013, a test filming was carried out in a bridge operation simulator. The data captures training session's three parts, briefing, a scenario, and debriefing - in all approximately $3 \mathrm{~h}$ of video-recorded data from one fixed camera. The material has served as a basis for early analysis and familiarisation with simulation training in the maritime domain. Second, a pilot study was conducted during November and December 2013. The training sessions recorded are part of a navigation course in the master mariner's program's second year. When filming, both fixed cameras were used in the briefing room and in the instructors' room, as well as a roving camera following the instructor during the exercise, capturing in all $15 \mathrm{~h}$ of simulation-based training of one student group and two different instructors. During November and December 2014, the main study was carried out, recording video data from the training sessions in the simulator. At this time, three different training sessions per exercise was recorded-approximately $60 \mathrm{~h}$ of simulation-based training. The aim was to collect data that captures all three instructors in the course, as well as different student groups, in all 40 students from the master mariner program. Fixed cameras were used in the briefing room to capture the briefing and debriefing phases, and a fixed camera was placed in the instructors' room to capture the instructors' use of monitoring 
technologies during exercises. In order to frame the action on the bridges, wall-mounted gopro cameras were used on each of the five simulators. When narrowing down the selection of video data for further analysis, six different scenarios and their subsequent debriefings emerged as especially interesting in regard to our tentative research questions. In all, the video data analysed in this study are based on approximately $30 \mathrm{~h}$ of training captured with multiple cameras.

\subsection{Analytical procedure}

When taking a situated approach, observation serves as a basis for theorising about what was seen in the data. The situated research tradition provides few theoretical stipulations of what to look for in the data; instead, we started with a sense of where to look. Generally, the focus is on the sequential order of social interaction, including talk, gestures, gaze, and body positions. There is one question about action that is consistently asked: Why that now? The analysis revolves around this rather simple question, trying to determine what an action means in relation to the preceding action, and what an action projects about the succeeding action (cf. Heath et al. 2010). In this later stage of analysis, the analyst(s) attempt to frame the observations in terms of theoretical concepts. In this way, the analytical results of this study are built bottom-up with an empirically driven approach to find common patterns of interaction during simulator-based exercises. When performed rigorously, such analyses provide new insights into collaborative work and learning with technologies.

In the scenarios selected for analysis, the students train to navigate in confined waters and traffic separation schemes (TSS) in restricted visibility and thus have to make use of both radar technologies and a combination of different COLREGs to master the scenario. These videos were reviewed to create a catalogue of data and organised in categories depending on the topic of the instructive talk that occurred during scenarios. Transcripts of the instructive episodes identified in the data corpus were made in the software Inqscribe in order to maintain a close link between the data material and the transcript. First, transcripts were developed to capture talk at a general level, i.e. what is being said. When continuing to narrow down the selection of what is analytically interesting, transcripts of certain interest were developed further, adding interactional details in terms of intonation, pause lengths, gestures, and bodily conduct, in order to also capture how things are said (Heath et al. 2010). These transcribed interactions were then analysed in detail, both individually and collaboratively, drawing on competencies from maritime instructors as well as educational and human factors researchers to ensure multiple perspectives on the data.

\section{Results}

What is clearly identified in all of our studies is the role and importance of the instructor's professional guidance, from briefing through scenario to debriefing. The instructions followed in the simulator environment consistently connect the simulated events to the conditions of work practice that are often encountered during on-board training, and to theoretical and abstract principles (Sellberg 2018; Sellberg and Lundin $2017 \mathrm{a}, \mathrm{b}$ ). This, in turn, is regarded as a prerequisite for simulator training; it 
must be relevant to the conditions of actual work on board a seagoing vessel. In the following sections, we elaborate on these findings.

\subsection{The importance of instructional support and assessments throughout training}

Although simulator-based instructors in maritime education might encounter challenges similar to those encountered in other domains, our results also reveal crucial differences. While simulation training in other realms often focuses on technical and non-technical skills, the need to instil general principles of good seamanship and international regulations is an essential part of basic maritime training (Sellberg and Lundin 2017a). The meaning of good seamanship and the rules of the sea are hard to teach in abstraction because their application relies on an infinite number of contingencies that have to be accounted for in every specific case (Sellberg 2018). During simulator-based training, these contingencies pose instructional challenges for the maritime instructor during the different phases of training.

Briefing is commonly focused on practical information regarding the upcoming scenario and the learning objectives, and it takes place in a classroom in close proximity to the simulators (Fig. 1). The spatial layout of the classroom sets up the framework for instruction, and the technologies used for instruction in this phase are common classroom technologies such as documents, PowerPoint presentations, and overhead sheets, which are prepared by the instructor beforehand. In this phase of training, the instructions given to the students are rather open and straightforward (Sellberg 2018). Examples of such open instructions are directives to 'follow COLREG' or to use the TRAIL function in a particular scenario. Before the scenario is played out, the specific contingencies of the scenario are unknown. On the one hand, the analysis reveals how the openness of the instructions was necessary in order to handle an infinite number of possible courses of events that may occur in the upcoming scenario. On the other hand, the students face a classical problem in following instructions: how to turn open and partial descriptions into practical action towards a desired outcome (cf. Suchman 2007).

After the briefing, a scenario plays out in the simulator. In the scenarios chosen for further analysis, the exercises take place in the dense traffic of the Dover Strait and in

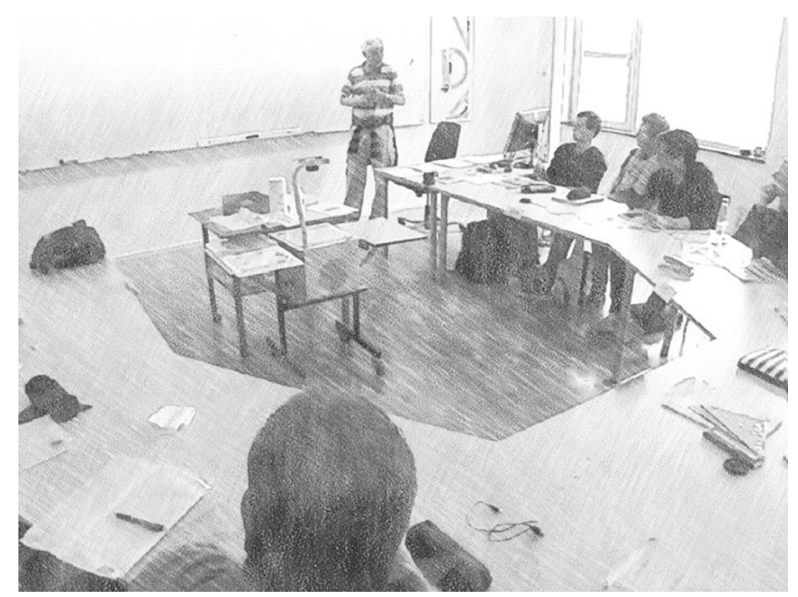

Fig. 1 The spatial layout of the briefing room 
the confined waters of the Great Belt Strait, where the students train in teams of two (as officer-of-the-watch and lookout) in bridge operation simulators. These kinds of exercises are used to train proficiency in handling the instruments on the ship's bridge, as well as in bridge teamwork and the application of the rules that regulate traffic at sea (COLREG). During the scenario phase, the instructor monitors the students' ongoing teamwork on the different bridges from the instructor's room (Fig. 2). Closely monitoring the students' actions is critical for laying the groundwork for assessing the students' course of action. Hence, during scenarios, assessment is a continuous and ongoing process that are necessary for the instructor's ability to recognise the fit or the gap between the learning objectives and the students' activities in the simulator (Sellberg and Lundin 2017a, b). These assessments turned out to rely both on technology - that is, on the monitoring technologies in the instructor's room and the radar technologies in the simulator-as well as on questions posed to the students.

When interactions between an instructor and students are taking place in the simulators, a variety of navigational technologies in a maritime context are essential as a basis for specific and timely instructions (Sellberg 2018; Sellberg and Lundin 2017a). For the instructor, being there in the midst of the action enables him or her to attend to specific details of the students' conduct, such as how they are managing their gaze and attention when integrating information from different sources on the bridge (Fig. 3). Similarly, in Sellberg and Lundin (2017b), the analysis shows how training coordination with other vessels in maritime traffic is sequentially organised in the simulator exercises, specifically focussing on the matter of temporality in instructional sequences. This means that assessments rely on the temporality of being either prospective or retrospective evaluations of the student's actions, because different temporalities offer different social and material conditions for their production. For example, when the assessment is targeting a manoeuvring action that is about to be carried out, the instructor must draw on his or her ability to evaluate how the situation will unfold over time, i.e. what is known as level three situation awareness (Endsley 1995). When the assessment is targeting a manoeuvring action that is already carried out, the instructor can rely on the historical traces that the TRAIL function leaves on the radar display as the basis for assessment.

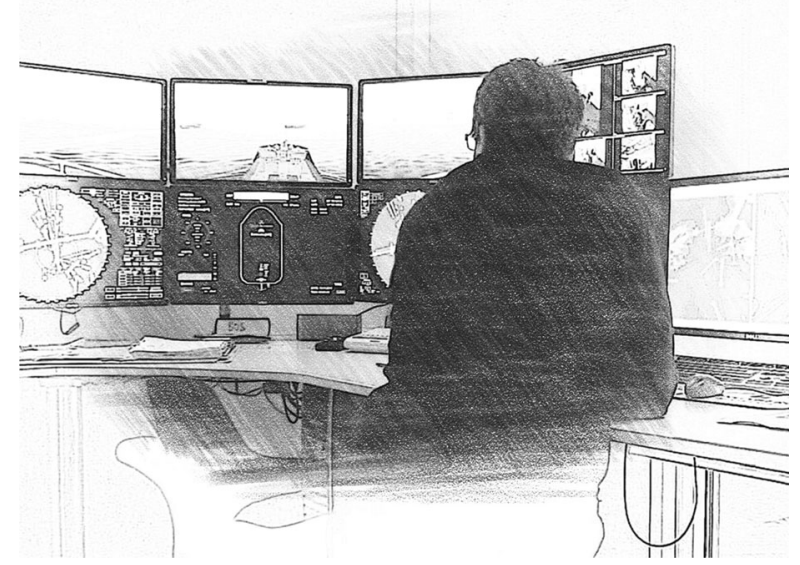

Fig. 2 Monitoring the students' actions from the instructors' room 


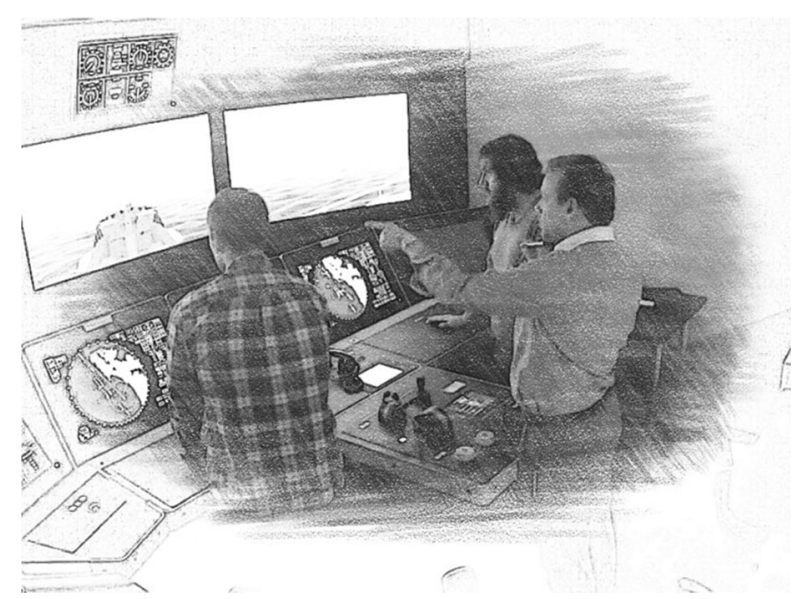

Fig. 3 A shared view of the situation enables specific details of the scenario to be highlighted and explained

The students' actions and understanding of the situation, which are shown in their answers to questions, are thoroughly critical to continue the instruction in a way that supports each student bridge team (Sellberg and Lundin 2017a, b). For example, the instructor can either clarify or correct the students' actions as necessary or just ratify their actions as correct behaviour. What is interesting is that these instructions, in relation to the instructions in the briefing phase, can be delivered in a way that takes the contingencies of specific situations into account (Sellberg 2018). In this way, instructions given during scenarios show how the earlier partial and open instructions apply to the specifics of a concrete situation. Such immediate and detailed instruction is known to 'keep the roof up', addressing skill acquisition issues that are difficult to address anywhere else and at any other point in time (Suchman 2007). In these instructions, both communication between vessels and matters of temporality become topics in their own right as the students train to coordinate in a timely manner with other vessels trafficking the same waters (Sellberg and Lundin 2017a, b). The instructor's contrasting between right and wrong conduct turned out to be of critical importance in creating figure and ground for showing students aspects of coordination that might be elusive to grasp for the students, such as what showing clear intentions, being proactive, and giving others enough time means in maritime traffic. The conclusion is that these instructions are targeting what is often referred to as a higher cognitive skill: third level situation awareness (cf. Endsley 1995).

Lastly, the debriefing phase provides the necessary basis for revisiting and learning from critical events (Fig. 4). At the core is the use of a playback that provides a bird's eye view of the prior scenario, which is recreating a shared view of how the different student teams navigate. The playback is essential to form a shared point of reference for demonstrating alternative solutions by contrasting what was done in the scenario with what should be done differently in order to follow the rules of the sea and maintain safe conduct in similar situations (Sellberg 2018). A range of different instructional resources can be combined in this process. The overview and dynamic playback of the scenarios can function as an essential background against which gestures, pointing, drawings, and conversation can be used in order to create a common view of typical problems and how these should be addressed. In this process, issues such as where to 


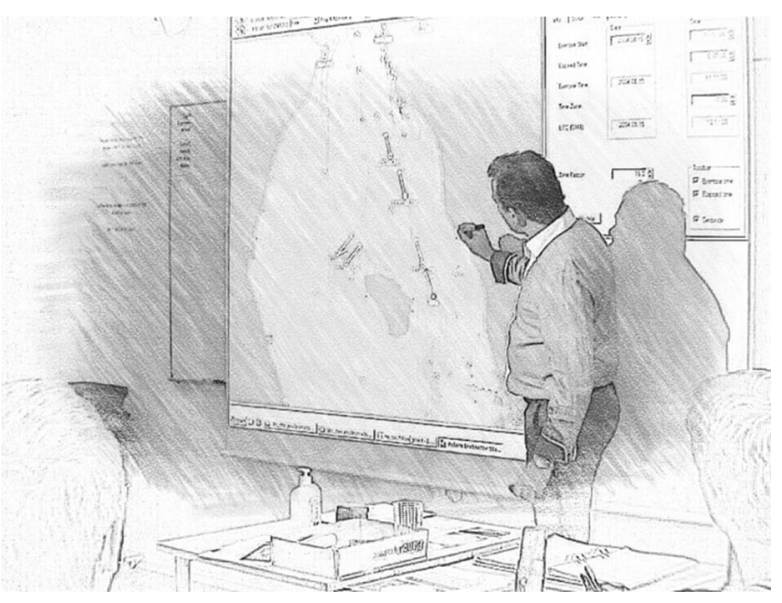

Fig. 4 A playback of the scenario is used during debriefing

look, which instruments to use, when to turn, and when to adjust speed can be elaborated upon to demonstrate how to keep a safe distance and how to show clear intentions to other ships. The application of the rules of the sea can be addressed in terms of practical and timely actions in relation to the ever-changing and situation-dependent character of navigation practice. Accordingly, the instructors' use of dynamic playbacks during debriefings offers opportunities to study rules in a context in which their meanings can be tied to situations and demonstrate preferable alternatives. Most importantly, the use of tools for navigation can represent a learning objective, something for students to master, and can also work as an instructional device of crucial importance in exhibiting nautical problems and demonstrating good seamanship in all its intricate details.

\subsection{Realism of simulator-based training as an interactional achievement}

The bridge operation simulator under study mimics several of the features of the bridge of a real ship, including the technologies used for navigating and manoeuvring the vessel as well as projections of the marine environment as seen through the front window of the bridge. However, because the bridge operation simulator is not a full-mission simulator with a motion platform that mimics the ship's movements, the sense of moving through the water is simulated through visual input rather than kinaesthetic or proprioceptive input. Exploring ship handling in bridge operation simulators as embodied activities shows how the lack of movement in the simulator reveals 'glitches' that are made relevant for instructional purposes in different situations (cf. Sellberg 2017b, p. 2311; Hindmarsh et al. 2014). When 'glitches' between the simulator and the ever-changing work setting on board a seagoing vessel occur, the instructors address these by coordinating talk and bodily conduct in giving instructions on the bridge operation simulator.

In line with the findings of Sellberg (2018) and Sellberg and Lundin (2017a, b), this study shows the rich variety of resources that are available to instructors and students in 
face-to-face interactions during scenarios in the bridge operation simulator. In the context of simulator-based training, the instructor coordinated his bodily conduct (i.e. gaze, bodily posture, and gestures) with talk that was oriented towards the simulator environment. The coordination of different representations enabled the students to grasp and communicate dynamic relations between elements in the world, a feature of using bodily conduct in conversation that can be seen in all types of settings.

Moreover, the coordination of different representations is recurrently oriented towards an imagined vessel and its movements in an imagined marine environment (see Sellberg $2017 \mathrm{~b}$ for a further discussion). This includes representations of the objects involved in ship handling, i.e. the rudders or the vessel, and the instructor's bodily conduct and talk to demonstrate their movements during these learning activities (Fig. 5). The events and activities that constitute ship handling are addressed during the instruction, in which the body is used as an instructional resource for enacting dynamic aspects of the ships' movements, such as sway and inertia. Following this, the results suggest that the coordination of talk and bodily conduct is used to fill in 'glitches' in the simulator environment, adding imagined layers of functionality where functionality is missing. Hence, the findings show how realism is an instructional concern as well as being an interactional achievement during training rather than a property of the simulator, and that this applies also in simulator-based maritime training.

These instructions seem to have the potential to prevent the types of training pitfalls caused by a lack of simulator fidelity that Hontvedt (2015a) commented on and warned about. Addressing inconsistencies between the simulation and the work setting are opportunities for instruction and discussions that can further the students' understanding of the work practice for which they are training (cf. Hindmarsh et al. 2014; Rystedt and Sjöblom 2012). That, in turn, requires fastidious instructors who closely monitor the students' work, ready to support them through the exercises in the simulator. The results emphasise how the instructional support of an experienced seafarer connects the simulated event to the students' future work practice and emphasises the relevance of theoretical and abstract knowledge in simulation training.

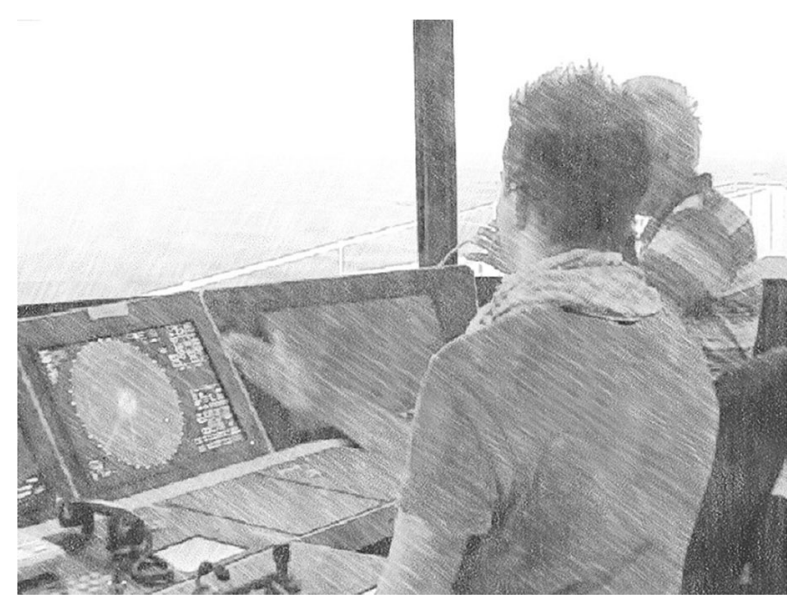

Fig. 5 Student and instructor collaboratively using their bodies to represent how a seagoing vessel would move during a turn 


\section{Conclusion and discussion}

The findings from the research project are summarised in the following points:

- The results emphasise the all over importance of systematic professional guidance and feedback in simulator-based training.

- The results show how detailed and timely instructions and assessments are critical for meeting the requirements of the STCW Convention through simulator-based training by connecting to the skills and knowledge necessary for becoming a competent master mariner.

- The results stress how simulator-based training is a hybrid activity, i.e. a protected area in which instructors can address a multitude of practical and theoretical issues relevant to the students' future work practice.

- The results highlight the role and importance of using the built-in technologies in the simulator environment as pedagogical tools for instructions throughout the different phases of the training.

Based on the results of the case under study, our conclusion is that current simulator-based training meets the requirements of the STCW Convention of training in both technical proficiency and non-technical skills, if the simulator-based activities are designed as training for maritime operations. The learning activities that take place in simulator environments are closely connected to what it means to act as a competent master mariner. Still, we argue that simulator-based training should not replace time at sea. The activities that take place during training in the simulator can be described as hybrid activities, which are a different sort of activity than those performed while spending time on board a vessel as an apprentice. The argument is that while time in the simulator is, to a large extent, used as a protected area for practicing situations that students have not yet mastered and to reflect on these efforts without the risks and time constraints involved in maritime practice, it constitutes an entirely different situation compared to practice on board. Further, time spent at sea might be critical to get first-hand experiences of work on board a ship that simulations cannot offer. Hence, simulator-based training should not replace periods of on-board practice for novice learners.

Our results also emphasise the role and importance of instructions that systemically bridge the two different practices of work on board a seagoing vessel and within a simulation for the students. Instructions should also make deliberate use of the similarities, differences, and irregularities between the different practices as pedagogical resources (cf. Hindmarsh et al. 2014). This imply that systematic professional guidance and feedback is critical in order to make simulator-based learning activities relevant to the wide range of tasks involved in manoeuvring seagoing vessels. Highlighting the details of the students' performance, together with explanations of general principles and formal rules, is at the core of demonstrating good seamanship and is key to further the students' understanding of professional competencies. The empirical results stress the role and importance of providing students with specific instructions both during scenarios and in debriefing, which is crucial for the process of connecting the simulator-based training to on-board work practices. Furthermore, our results show that debriefing models recommending a linear chronological order of discrete phases 
could be misleading. Although this structure provides an all over resource, connecting principles and rules to the multitude of specific circumstances in the training scenarios are recurrently performed throughout the debriefings.

The results contribute to a number of studies that address changes in educational practices when simulator technologies are put to use in maritime training. As seen in Sellberg (2017a), there is still a need for research that explores the use of simulators in maritime training and assessment. While this research project has focused on interactions during training in a single-case design, there is still a need for research that analyses other training models in interactional detail in order to validate their usefulness in simulator-based environments. Moreover, the limited scope has left unanswered important questions in regard to simulator-based summative assessment. There are, however, several emerging challenges in this field because technologies of the near future, such as unmanned vessels, will pose new challenges for educators. As maritime education trains students for a global industry in one of the most safety-critical work domains in the world, there is a need to perform research in maritime training that can further our knowledge of how safety cultures can be learned in everyday simulation practice.

Acknowledgements Parts of this article were previously presented at the International Association of Maritime Universities Annual General Assembly (IAMU AGA2017), Varna, Bulgaria, 11-14 October 2017. It has been substantially reworked with several amendments for publication in WMU Journal of Maritime Affairs.

We are also most grateful to the instructors and master mariner students at the simulator centre for their participation in the project.

Funding information The research project is financed by four parties: The University of Gothenburg Learning and Media Technology Studio (LETStudio); The Linnaeus Centre for Research on Learning, Interaction and Mediated Communication in Contemporary Society (LinCS); Department of Mechanics and Maritime Sciences at Chalmers University of Technology; and Department of Education, Communication and Learning at University of Gothenburg.

Open Access This article is distributed under the terms of the Creative Commons Attribution 4.0 International License (http://creativecommons.org/licenses/by/4.0/), which permits unrestricted use, distribution, and reproduction in any medium, provided you give appropriate credit to the original author(s) and the source, provide a link to the Creative Commons license, and indicate if changes were made.

\section{References}

Ali A (2008) Role and importance of simulator instructor. Int J Mar Navig Saf Sea Transport 2(4):423-427

Chauvin C, Clostermann JP, Hoc JM (2009) Impact of training programs on decision-making and situation awareness of trainee watch officers. Saf Sci 47:1222-1231. https://doi.org/10.1016/j.ssci.2009.03.008

Dahlström N, Dekker S, Van Winsen R, Nyce J (2009) Fidelity and validity of simulator training. Theor Issues Ergon 10:305-314. https://doi.org/10.1080/14639220802368864

Derry S, Pea R, Barron B, Engle R, Erickson R, Goldman R, Hall R, Koschmann T, Lemke J, Sherini M, Sherini B (2010) Conducting video research in the learning sciences: guidance on selection, analysis, technology, and ethics. J Learn Sci 19:3-53. https://oi.org/10.1080/10508400903452884

Dieckmann P, Reddersen S, Zieger J, Rall M (2008) A structure for video-assisted debriefs in simulator-based training of crisis recourse management. In: Kyle R, Murray BW (eds) Clinical simulation: operations, engineering, and management. Academic Press, Burlington, pp 667-676

Emad GR (2010) Introduction of technology into workplace and the need for change in pedagogy. Procd Soc Behav 2:875-879. https://doi.org/10.1016/j.sbspro.2010.03.119 
Emad GR, Roth WM (2008) Contradictions in the practices of training for and assessment of competency: a case study from the maritime domain. Educ Train 50:260-272. https://doi.org/10.1108 /00400910810874026

Endsley MR (1995) Toward a theory of situation awareness in dynamic systems. Hum Factors 37:32-64. https://doi.org/10.1518/001872095779049543

Erickson F (2007) Ways of seeing video: toward a phenomenology of viewing minimally edited footage. In: Goldman R, Pea R, Barron B, Derry S (eds) Video research in the learning sciences. New York. Lawrence Erlbaum Associates, New Jersey, pp 145-155

Escher C, Rystedt H, Creutzfeldt J, Meurling L, Nyström S, Dahlberg J, Edelbring S, Nordahl Amorøe T, Felländer-Tsai L, Abrandt-Dahlgren M (2017) Method matters: impact of in-scenario instruction on simulation-based team training. Adv Simul. https://doi.org/10.1186/s41077-017-0059-9

Fanning RM, Gaba DM (2007) The role of debriefing in simulation-based learning. Simul Healthc 2:115-125. https://doi.org/10.1097/SIH.0b013e3180315539

Flin R (2008) Safety at the sharp end: a guide to non-technical skills. Taylor \& Francis Group Ltd, Abingdon

Gekara VO, Bloor M, Sampson H (2011) Computer-based assessment in safety-critical industries: the case of shipping. J Vocat Educ Train 63:87-100. https://doi.org/10.1080/13636820.2010.536850

Goodwin C (1994) Professional vision. Am Anthropol 96:606-633. https://doi.org/10.1525/aa.1994.96.3.02 a00100

Greiffenhagen C (2008) Unpacking tasks: the fusion of new technology with instructional work. Comp Support Coop Work 17:35-62. https://doi.org/10.1007/s10606-007-9068-X

Hamstra SJ, Brydges R, Hatala R, Zendejas B, Cook D (2014) Reconsidering fidelity in simulation-based training. Acad Med 89:387-392. https://doi.org/10.1097/ACM.0000000000000130

Hanzu-Pazara R, Barsan E, Arsenie P, Chiotoroiu L, Raicu G (2008) Reducing of maritime accidents caused by human factors using simulators in training process. J Marit Res 5(1):3-18

Hanzu-Pazara R, Arsenie P, Hanzu-Pazara L (2010) Higher performance in maritime education through better trained lecturers. TransNav Int J Mar Navigat Saf Sea Transport 4(1):87-93

Heath C, Hindmarsh J, Luff P (2010) Video in qualitative research: analysing social interaction in everyday life. SAGE Publications Ltd, London

Hindmarsh J, Hyland L, Banerjee A (2014) Work to make simulation work: 'realism', instructional correction and the body in training. Discourse Stud. 16:247-269. https://doi.org/10.1177/1461445613514670

Hontvedt M (2015a) Professional vision in simulated environments: examining professional maritime pilots' performance of work tasks in a full-mission ship simulator. Learn Cult Soc Interact 7:71-84. https://doi. org/10.1016/j.lcsi.2015.07.003

Hontvedt M (2015b) Simulations in maritime training: a video study of the socio-technical organisation of ship simulator training. Dissertation, University of Oslo

Hontvedt M, Arnseth HC (2013) On the bridge to learn: analysing the social organization of nautical instruction in a ship simulator. Comput Support Collab Learn. 8:89-112. https://doi.org/10.1007 /s11412-013-9166-3

Hutchins E (1995) Cognition in the wild. MIT Press, Cambridge

Johansson E, Lindwall O, Rystedt H (2017) Experiences, appearances, and interprofessional training: the instructional use of video in post-simulation debriefings. Comput Support Learn 12:91-112. https://doi. org/10.1007/s11412-017-9252-z

Johnson E (2007) Surgical simulators and simulated surgeons: reconstituting medical practice and practitioners in simulations. Soc Stud Sci 37:585-608. https://doi.org/10.1177/0306312706072179

Ludvigsen S, Arnseth HC (2017) Computer-supported collaborative learning. In: Duval E, Sharples M, Sutherland R (eds) Technology enhanced learning. Springer International Publishing, New York, pp 47-58

Lützhöft M, Nyce JM, Petersen ES (2010) Epistemology in ethnography: assessing the quality of knowledge in human factors research. Theor Issues Ergon. 11:532-545. https://doi.org/10.1080/14639220903247777

Maran NJ, Glavin R (2003) Low- to high-fidelity simulation: a continuum of medical education? Med Educ 37:22-28. https://doi.org/10.1046/j.1365-2923.37.s1.9.x

Neill MA, Wotton K (2011) High-fidelity simulation debriefing in nursing education: a literature review. Clin Simul Nurs 7:e161-e168. https://doi.org/10.1016/j.ecns.2011.02.001

Roth WM, Jornet A (2015) Situational awareness as an instructable and instructed matter in multi-media supported debriefing: a case study from aviation. Comp Support Comp W 24:461-508. https://doi. org/10.1007/s10606-015-9234-5

Rystedt H, Sjöblom B (2012) Realism, authenticity, and learning in healthcare simulations: rules of relevance and irrelevance as interactive achievements. Instr Sci 40:785-798. https://doi.org/10.1007 /s11251-012-9213-x 
Sampson H, Gekara V, Bloor M (2011) Water-tight or sinking? A consideration of the standards of the contemporary assessment practices underpinning seafarer licence examinations and their implications for employers. Marit. Policy Manag. https://doi.org/10.1080/03088839.2010.533713

Saus ER, Johnsen BH, Eid J (2010) Perceived learning outcome: the relationship between experience, realism, and situation awareness during simulator training. Int Marit Health 61(4):258-264

Sellberg C (2017a) Simulators in bridge operation training and assessment: a systematic review and qualitative synthesis. WMU J Marit Affairs 16:247-263. https://doi.org/10.1007/s13437-016-0114-8

Sellberg C (2017b) Representing and enacting movement: the body as an instructional resource in a simulatorbased environment. Educ Inf Technol 22:2311-2332. https://doi.org/10.1007/s10639-016-9546-1

Sellberg C (2018) From briefing, through scenario, to debriefing: the maritime instructor's work during simulator-based training. Cogn Technol Work 20:49-62. https://doi.org/10.1007/s10111-017-0446-y

Sellberg C, Lundin M (2017a) Demonstrating professional intersubjectivity: the instructor's work in simulatorbased learning environments. Learn Cult Soc Interact. 13:60-74. https://doi.org/10.1016/j. lcsi.2017.02.003

Sellberg C, Lundin M (2017b) Tasks and instructions on the simulated bridge: discourses of temporality in maritime training. Discourse Stud. https://doi.org/10.1177/1461445617734956

Suchman L (2007) Human-machine reconfigurations: plans and situated actions, 2nd edn. Cambridge University Press, Cambridge

Wickers MP (2010) Establishing the climate for a successful debriefing. Clin Simul Nurs 6:e83-e86. https://doi.org/10.1016/j.ecns.2009.06.003 